\title{
A Review of the Invasive Mosquitoes in Europe: Ecology, Public Health Risks, and Control Options
}

\author{
Jolyon M. Medlock, Kayleigh M. Hansford, ${ }^{1}$ Francis Schaffner, ${ }^{2,3}$ Veerle Versteirt, ${ }^{4}$ \\ Guy Hendrickx, ${ }^{2}$ Herve Zeller, ${ }^{5}$ and Wim Van Bortel ${ }^{5}$
}

\begin{abstract}
There has been growing interest in Europe in recent years in the establishment and spread of invasive mosquitoes, notably the incursion of Aedes albopictus through the international trade in used tires and lucky bamboo, with onward spread within Europe through ground transport. More recently, five other non-European aedine mosquito species have been found in Europe, and in some cases populations have established locally and are spreading. Concerns have been raised about the involvement of these mosquito species in transmission cycles of pathogens of public health importance, and these concerns were borne out following the outbreak of chikungunya fever in Italy in 2007, and subsequent autochthonous cases of dengue fever in France and Croatia in 2010. This article reviews current understanding of all exotic (five introduced invasive and one intercepted) aedine species in Europe, highlighting the known import pathways, biotic and abiotic constraints for establishment, control strategies, and public health significance, and encourages Europe-wide surveillance for invasive mosquitoes.
\end{abstract}

Key Words: Aedes—Europe—Invasive mosquitoes—Vector-borne disease.

\section{Introduction}

$\mathbf{T}$ HE RECENT EMERGENCE OF BLUETONGUE VIRUS in northern Europe, large scale outbreaks of West Nile fever in North America, and an outbreak of chikungunya fever in Italy, reminds us of the very real risk of exotic pathogens being transported to Europe throughout the rapidly-changing, interconnected world. Such connectivity also increases the possibilities for movement of disease vectors, particularly mosquitoes and ticks, and this has created novel scenarios whereby established exotic vectors have facilitated transmission of previously tropical and subtropical pathogens in Europe.

Continued vector importation events, in combination with climatic and environmental changes, increase the likelihood of the establishment and adaptation of vectors to new environments. In the case of exotic invasive mosquitoes, new disease vector species are frequently being recorded in Europe, and the spread of these species within Europe is evidenced by the growing list of countries known to harbor certain species.

To address this problem, and to facilitate Europe-wide collaboration, the European Centre for Disease Prevention and Control (ECDC) established VBORNET, a network of European medical entomologists and public health experts, in order to assist ECDC activities involving arthropod vector surveillance within the European Union, and consequently to improve preparedness for vector-borne diseases (www.vbornet.eu).

This article focuses purely on the invasive mosquito species that have been imported into Europe over the past 40 years. The aim of this review is to provide an update on the current status of introduced invasive and intercepted aedine mosquito species, detail their geographic spread thus far, assess their pathways for importation and onward dissemination, to analyze their known vector status and potential public health risks for Europe, detail their biology, and to assess climatic thresholds for survival and strategies for control.

\footnotetext{
${ }^{1}$ Medical Entomology and Zoonoses Ecology Group, Microbial Risk Assessment, Emergency Response Division, Health Protection Agency, Porton Down, Salisbury, United Kingdom.

${ }^{2}$ Avia-GIS, Agro-Veterinary Information and Analysis, Zoersel, Belgium.

${ }^{3}$ Institute of Parasitology, University of Zurich, Zurich, Switzerland.

${ }^{4}$ Institute of Tropical Medicine, Antwerp, Belgium.

${ }^{5}$ European Centre for Disease Prevention and Control, Stockholm, Sweden.
} 
Major generic changes within the tribe aedini were recently published (Reinert 2000; Reinert et al. 2004, 2006, 2008), leading to scientific debate and two or more names being simultaneously used for a single taxon. In this article we use the traditional names, with alternate names also shown: Aedes aegypti, also known as Stegomyia aegypti sensu (Reinert et al. 2004); Aedes albopictus, also known as Stegomyia albopicta sensu (Reinert et al. 2004); Aedes atropalpus, also known as Ochlerotatus atropalpus sensu (Reinert et al. 2004); Georgecraigius atropalpus sensu (Reinert et al. 2006); Aedes japonicus, also known as Ochlerotatus japonicus sensu (Reinert et al. 2004); Hulecoeteomyia japonica sensu (Reinert et al. 2006); Aedes koreicus, also known as Ochlerotatus koreicus sensu (Reinert et al. 2004); Hulecoeteomyia koreica sensu (Reinert et al. 2006); and Aedes triseriatus, also known as Ochlerotatus triseriatus sensu (Reinert et al. 2004).

\section{Overview of Invasive Mosquito Species in Europe}

\section{Aedes albopictus}

Of the invasive mosquito species discovered in Europe, the Asian Tiger mosquito, Aedes (Stegomyia) albopictus, probably presents the major threat to public health in Europe. It is listed as one of the top 100 invasive species by the Invasive Species Specialist Group (Invasive Species Specialist Group 2009), and is considered to be the most invasive mosquito species in the world. Aedes albopictus originated in Southeast Asia, but has spread during the last 30-40 years (Paupy et al. 2009) to North, Central and South America, parts of Africa, northern Australia, and several countries in Europe. Since its first appearance in Albania in 1979 and Italy in 1990, A. albopictus has been reported in 20 European countries (Fig. 1 and Table 1), including Albania, Belgium, Bosnia and Herzegovina, Croatia, France (including Corsica), Germany, Greece, Italy (including Sardinia and Sicily), Malta, Monaco, Montenegro, the Netherlands, San Marino, Serbia, Slovenia, Spain, Switzerland, and the Vatican City (European Centre for Disease Prevention and Control 2009; Gatt et al. 2009: Petric 2009), as well as Bulgaria, where it has been recently reported $(\mathrm{O}$. Mikov, personal communication) and Turkey (O. Alten, K. Oter; personal communication). It is unclear whether populations in some countries of northwestern Europe will establish, particularly into the Netherlands, as the populations found in greenhouses are thought to be non-diapausing strains imported from southern China on lucky bamboo (Scholte et al. 2007). However, strains recently introduced to the

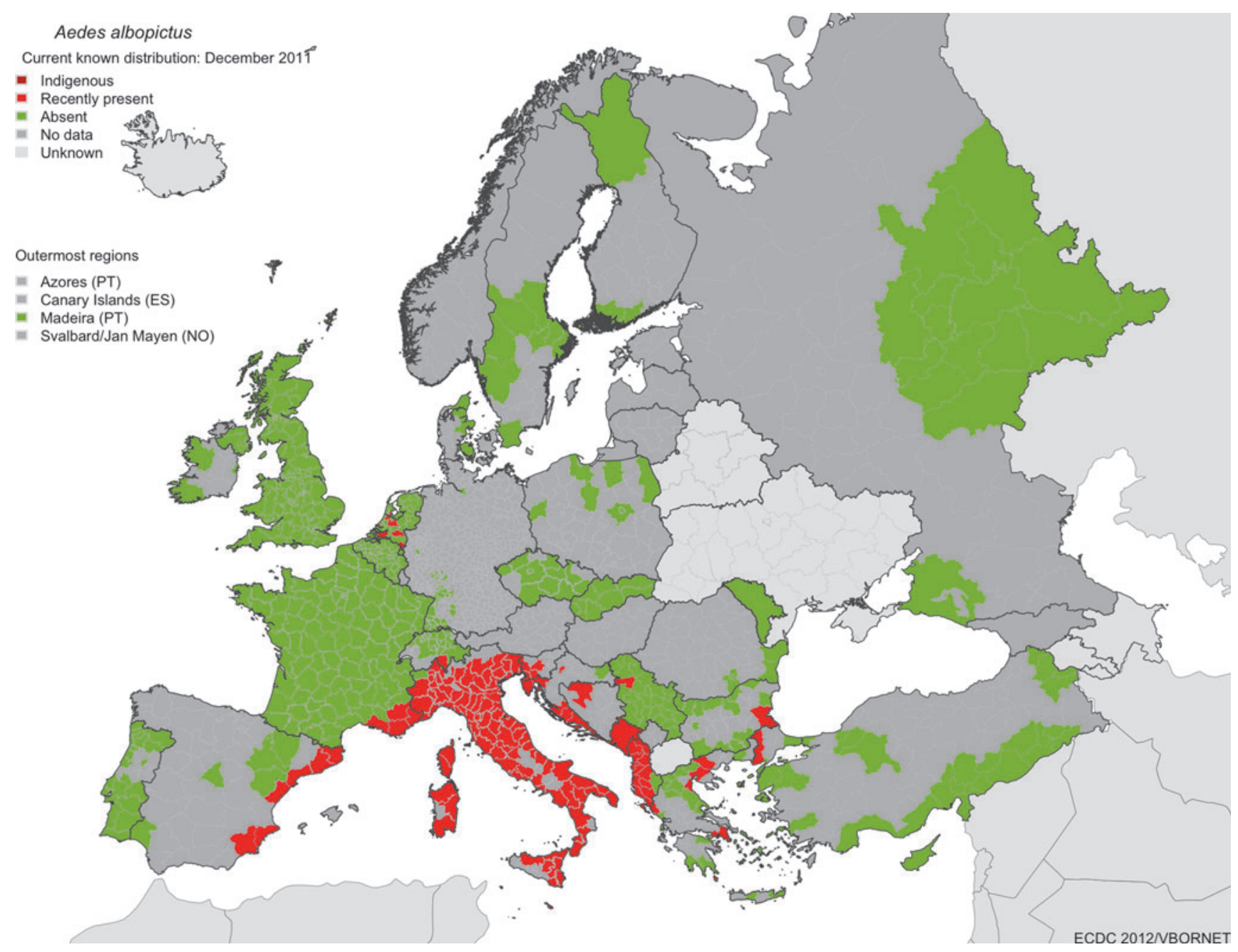

FIG. 1. The currently known distribution of Aedes albopictus in Europe in September 2011. The most recent updated map can be downloaded from www.vbornet.eu (ES, Spain; PS, Portugal; NO, Norway). 
Table 1. Overview of the Importation Routes of the Exotic Aedine Mosquitoes Established OR INTERCEPTED IN EUROPE

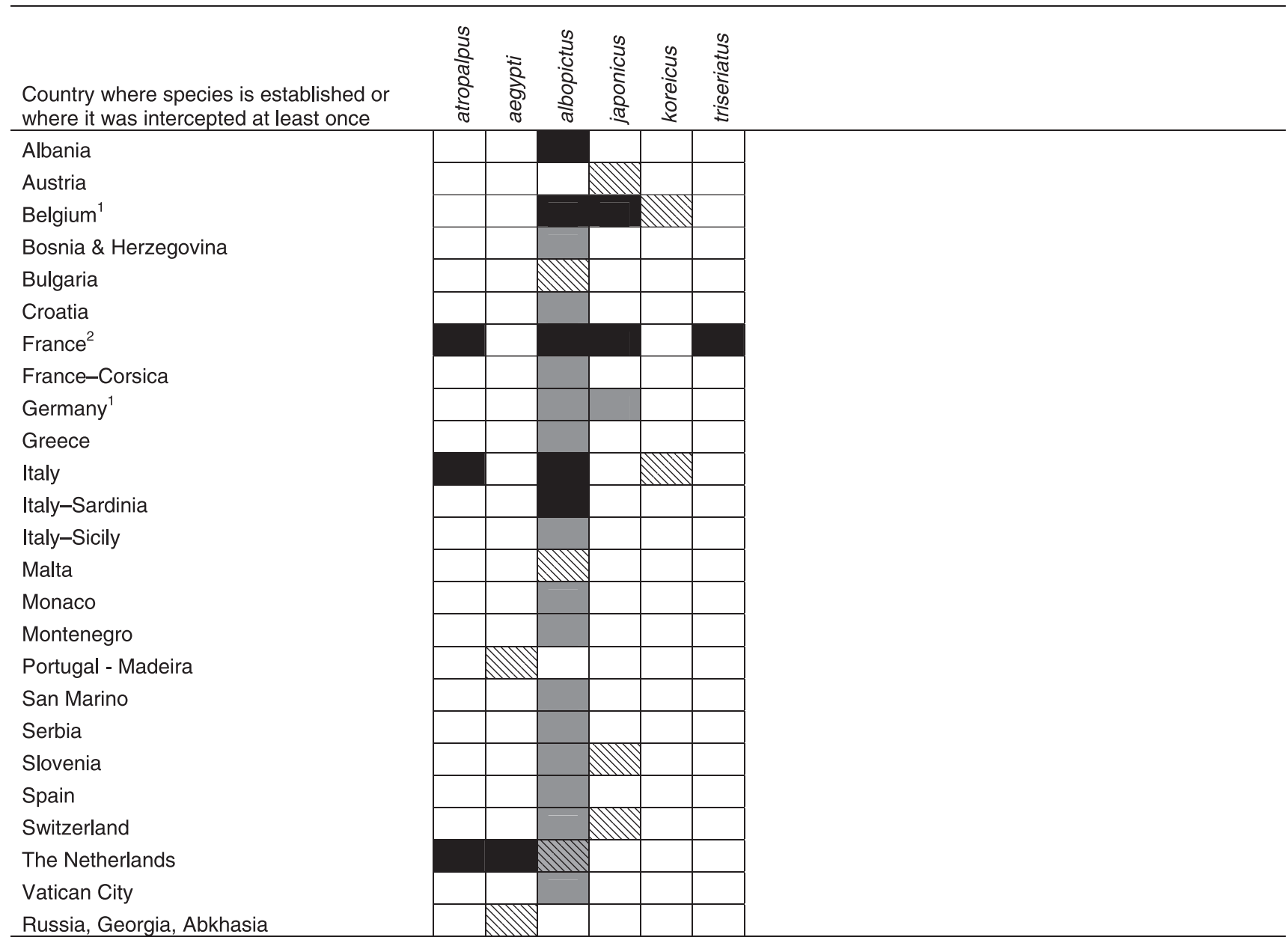

Used tire trade

Both used tire and Lucky bamboo trades

Public/private ground transport

Unknown route of import

Species not present

${ }^{1}$ Aedes albopictus was not able to establish in Belgium or Germany.

${ }^{2}$ Ae. albopictus established successfully via ground transport.

Netherlands from southern Florida via the tire trade might be more successful in becoming established if they are not eliminated (Scholte et al. 2010). The species is now widely established and reportedly a nuisance species, particularly in Italy (Scholte et al. 2007), parts of France (Vazeille et al. 2008) and Spain (Aranda et al. 2006), and other locations in the Mediterranean (Fig. 1). In Italy, the most heavily infested country in Europe, the species occupies most areas of the country below an altitude of $600 \mathrm{~m}$, in particular the FriuliVenezia-Giulia region, large parts of the Lombardia and Emilia Romagna regions, and coastal areas of central Italy, and is highly abundant in many urban areas (European Centre for Disease Prevention and Control 2009; Valerio et al. 2009). In France, the species was first detected in 1999, and since 2004 has been spreading from Menton, Alpes-Maritimes, to the areas of Var (in 2007), and Bouches-du-Rhône (in
2009), as well as Corsica (2005). It is estimated that the infested area increased from $1000 \mathrm{~km}^{2}$ in 2008 to more than $4000 \mathrm{~km}^{2}$ in 2010. Though established populations in France are currently only found on the east Mediterranean coastline, A. albopictus has recently been sporadically detected as far west as the Pyrénées-Orientales, at the Spanish border in the south, and Saône-et-Loire in the north (European Centre for Disease Prevention and Control 2011).

As with all of the invasive aedine species, the eggs of A. albopictus have successfully been transported globally via the used tire trade and the importation of lucky bamboo. Female mosquitoes lay their eggs in a range of container habitats. These eggs are oviposited above the water line, and are able to withstand desiccation and prolonged periods out of water. Containers such as tires and those containing water-dwelling plants are then exported to new geographic 
regions, and subsequent inundation by water facilitates egg hatching, with populations arising in new locations, assuming local climatic conditions are suitable. Further local dispersal then occurs via road vehicles (Table 1). These methods of dispersal are extremely effective in moving this species across continents, and will no doubt continue to be pivotal in the ever-increasing distribution of $A$. albopictus. Consideration of these dispersal mechanisms, combined with current risk mapping and climate change assessments, suggest that further expansion across much of Europe is probable (Benedict et al. 2007; European Centre for Disease Prevention and Control 2009). Undoubtedly, its success in colonizing new geographic locations is due to its ability to adapt to different climates through the production of cold-resistant eggs, with temperate strains surviving cold winters in northern latitudes. Like many invasive mosquito species, its preference for container habitats (e.g., tires and vases) in domestic settings has resulted in increased potential for contact with humans.

Aedes albopictus is an important known vector of chikungunya virus (CHIKV). It was the primary vector involved in outbreaks of CHIKV on La Reunion Island in 2005-2007 (Pialoux et al. 2007), in Italy in 2007 (Angelini et al. 2007;
Rezza et al. 2007), and in France in 2010 (Gould et al. 2010; Grandadam et al. 2011). Aedes albopictus has also been implicated as a vector of dengue virus (DENV), causing outbreaks on La Reunion Island in 1977-1978 (Coulanges et al. 1979), Hawaii in 2001-2002 (Effer et al. 2005), on La Reunion Island again in 2004 (Pierre et al. 2005), Mauritius in June 2009 (Ramchurn et al. 2009), and France and Croatia during 2010 (La Ruche et al. 2010; Gjenero-Margan et al. 2011). The cases reported in France and Croatia were the first autochthonous dengue cases to be reported in Europe since the outbreak in Greece in 1927-1928 (La Ruche et al. 2010).

Aedes albopictus is also a known vector of Dirofilaria (the filarial nematodes $D$. immitis and $D$. repens), a parasite transmitted primarily between dogs and mosquitoes, but which can also affect humans. Recent evidence has shown transmission of the parasite by Italian A. albopictus populations (Cancrini et al. 2003a,2003b), coupled with an increase in the prevalence of human dirofilariasis in Italy (Pampiglione et al. 2001).

A number of other viruses important to human health have been isolated from field-collected $A$. albopictus in different countries, and laboratory transmission of such viruses by this species has been demonstrated (Paupy et al. 2009) (Table 2).

Table 2. Overview of the Vector Status of the Exotic Aedine Mosquito Species Intercepted OR Established IN EUROPE

\begin{tabular}{|c|c|c|c|c|c|c|c|c|}
\hline pathogen & & & 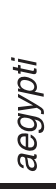 & $\begin{array}{l}\frac{n}{2} \\
\frac{0}{2} \\
\frac{0}{2} \\
\frac{0}{2}\end{array}$ & 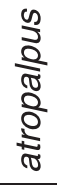 & 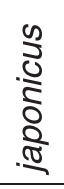 & 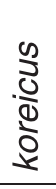 & 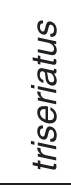 \\
\hline \multirow[t]{12}{*}{ Viruses } & Alphavirus & Chikungunya & & & & & & \\
\hline & & Eastern Equine encephalitis & & & & & & \\
\hline & & La Crosse & & & & & & \\
\hline & & Venezuelan Equine encephalitis & & & & & & \\
\hline & & Western equine encephalitis & & & & & & \\
\hline & Flavivirus & Dengue & & & & & & \\
\hline & & Japanese encephalitis & & & & & & \\
\hline & & St Louis encephalitis & & & & & & \\
\hline & & West Nile & & & & & & \\
\hline & & Yellow fever & & & & & & \\
\hline & & Zika & & & & & & \\
\hline & Bunyavirus & Jamestown Canyon & & & & & & \\
\hline Nematodes & Dirofilaria & $D$. immitis and $D$. repens & & & & & & \\
\hline
\end{tabular}

Proven vector in the field

Found infected in field and laboratory competence studies having potential role as vector, but no proven vector in the field

Only laboratory competence studies having showed potential involvement in transmission No vector or not known 
These include Eastern equine encephalitis virus (EEEV) (Mitchell et al. 1992; Turell et al. 1994), La Crosse virus (LACV) (Grimstad et al. 1989; Gerhardt et al. 2001), Venezuelan equine encephalitis virus (VEEV) (Beaman and Turell 1991; Turell and Beaman 1992), West Nile virus (WNV) (Holick et al. 2002; Sardelis et al. 2002c), and Japanese encephalitis virus (JEV) (Paupy et al. 2009).

Even in the absence of disease transmission, $A$. albopictus is a serious nuisance biting species, particularly in urban areas, where control can become an economic burden to local municipalities due to numerous larval development sites (Scholte et al. 2007). Although not currently a problem, resistance to insecticides (e.g., pyrethroids) has been detected in populations in Thailand, Japan, and La Reunion, and the spread of this resistance could have a serious impact on current control strategies (Kawada et al. 2010; Tantely et al. 2010). In summary, the ability of $A$. albopictus to adapt to new environments, its predicted spread and establishment in Europe, and its confirmed involvement in pathogen transmission cycles makes the surveillance and control of this species hugely important.

\section{Aedes aegypti}

Aedes (Stegomyia) aegypti is another important invasive mosquito species that could potentially have an impact on European public health. It is found throughout tropical and subtropical regions of the Americas, Africa, and Asia, as well as the southeastern U.S., the Indian Ocean islands, and northern Australia (Soumahoro et al. 2010). This species was previously established in Europe up to the beginning of the 20th century as far north as Brest and Odessa (Reiter 2010), and has recently re-established in Europe in Madeira (Almeida et al. 2007), and around the Black Sea in southern Russia, Abkhazia, and Georgia (Yunicheva et al. 2008; G. Babuadze pers. comm.). It was then reported for the first time in the Netherlands in 2010, associated with imported used tires, but the temperate climate and prompt implementation of control measures suggests this species is unlikely to become established there (Scholte et al. 2010).

$A$. aegypti does not overwinter like $A$. albopictus, but can utilize sheltered sites in a domestic setting, which provides protection against environmental conditions and numerous aquatic habitats suitable for oviposition. There are no climatic reasons why this species could not become widely established in southern Europe, if re-introduced (Reiter 2010). Concern has been raised that this species could be imported from Madeira to mainland Europe, spreading to its former range in southern Europe, where it was implicated in previous large outbreaks caused by yellow fever virus (YFV) and DENV (Fontenille et al. 1997). This species is highly adapted to urban environments and its propensity to seek human blood meals and feed on multiple persons during one gonotrophic cycle increases the potential for disease transmission. As has been proven in Madeira, it is also difficult to control.

Major dengue fever epidemics due to A. aegypti occur in the Americas, Southeast Asia, and the western Pacific, and the disease is now endemic in more than 100 countries worldwide, with an estimated 50 million infections every year (WilderSmith et al. 2010). The incidence of this disease has increased dramatically, as has the incidence of the more severe dengue hemorrhagic fever (DHF) (Wichmann and Jelinek 2003). A. aegypti was also responsible for large epidemics of dengue in Greece in 1927-1928 (Rosen 1986), and outbreaks of CHIKV have occurred more recently in Kenya, India, other parts of Asia, and the Comoros Islands (Gould and Higgs 2009).

A. aegypti is also a highly effective vector of YFV, a disease found in west, central, and east Africa (where large severe epidemics have been recorded, with tens of thousands of deaths), and in South America. Historically, a YF outbreak occurred in Wales in the 19th century following importation of $A$. aegypti together with infected passengers aboard a boat (Buchanan 1865), and a large outbreak was also reported in Barcelona in 1821 (Chastel 1999).

$A$. aegypti has been suggested as a vector of Zika virus (ZIKAV), owing to isolation of the virus from field collections of mosquitoes (Marchette et al. 1969), and virus transmission has been demonstrated under laboratory conditions (Boorman and Porterfield 1956) (Table 2). ZIKAV is a flavivirus related to YFV, DENV, WNV, and JEV. It causes a relatively mild disease characterized by rash, arthralgias, and conjunctivitis. The first outbreak of ZIKAV to be reported outside its usual geographical range (Africa and Asia) was in 2007 on Yap Island, where 185 confirmed or suspected cases were reported (Hayes 2009).

\section{Aedes japonicus}

Aedes (Finlaya) japonicus is also an important invasive species globally. It originated in eastern Asia and the Far East (Tanaka et al. 1979), but has become widely established in North America and central Europe. Populations are now widely established in northern Switzerland and southern Germany, with former reports from France, where it was eradicated, and Belgium (Schaffner et al. 2003,2009; Versteirt et al. 2009; Becker et al. 2011). A. japonicus appears not to have spread in Belgium, although in Switzerland its range has expanded in all directions. It can also be found widespread in southwest Germany, where large areas in the state of BadenWürttemberg are now infested (e.g., around the Stuttgart area) (Becker et al. 2011; Huber et al. 2011; Schneider 2011). Recently it has been found established in a wide area of southeastern Austria and neighboring Slovenia, from Graz to Maribor (B. Seidel, personal communication).

Importation pathways are believed to be partly due to the used tire trade (Table 1); however, in Switzerland the sites of initial importation are not clear, as no evidence of importation of used tires has been reported within the colonized area (Schaffner et al. 2009). This mosquito is a container habitat species, adapting to urban areas where it is a nuisance biting pest. In Switzerland it has been found utilizing cemetery vases, fountains, water casks, and catch basins as aquatic habitats (Schaffner et al. 2009). Its ability to withstand winter temperatures and the speed of its dispersal in Switzerland suggest that $A$. japonicus could become more widely established in Europe. This spread could be exacerbated by its exploitation of less specialized aquatic habitats (e.g., high tolerance to organic concentrations) (Versteirt et al. 2009) compared to A. albopictus (Schaffner et al. 2003).

Although not considered an important disease vector, its proliferation in urban areas and its propensity to feed on a range of hosts shows its importance as a nuisance biting pest. Studies demonstrating its competence as a vector of a number of arboviruses suggest that this species has the potential to become involved in disease transmission (Table 2). Fieldcollected A. japonicus have been found to be positive for WNV 
on a number of occasions in the U.S. (Andreadis et al. 2001), and laboratory studies show it is a competent vector of WNV (Sardelis and Turell 2001; Turell et al. 2001), JEV (Takashima and Rosen 1989), and LACV (Sardelis et al. 2002a), and a moderately efficient vector for EEEV (Sardelis et al. 2002b), and St. Louis encephalitis virus (SLEV) (Sardelis et al. 2003). However, its role in the transmission of these viruses under natural conditions is unclear (Versteirt et al. 2009).

\section{Aedes atropalpus}

Aedes (Ochlerotatus) atropalpus is a North American invasive mosquito that has recently been reported in Europe via the commercial transport of used tires. It was initially reported in Italy in 1996 (Romi et al. 1997), more recently in France in 2003 and 2005 (S. Chouin and F. Schaffner, unpublished data), and in the Netherlands in 2008 and again in 2010 (Scholte et al. $2009,2010)$. In the Netherlands, this species has been found breeding in larval habitats other than tires (Scholte et al. 2010), and climate-based assessments suggest that climatic constraints in northern Europe are not likely to limit its expansion within and beyond the Netherlands (Scholte et al. 2009).

This mosquito species has not been implicated in virus transmission cycles, but field-collected mosquitoes in North America have been to be found positive for WNV (Turell et al. 2005). Laboratory competency studies have shown the ability of A. atropalpus to transmit LACV (Freier and Beier 1984), WNV (Turell et al. 2001), and other arboviral encephalitides, but its importance as a vector of infectious diseases is still not clear (Scholte et al. 2009). The propensity of this species to feed on a range of hosts (including humans), and studies demonstrating its competence as a vector of a number of arboviruses suggests that this species has the potential to become involved in disease transmission.

\section{Aedes triseriatus}

Aedes (Protomacleaya) triseriatus is a North American species that has been found in France, intercepted in a batch of used tires from the U.S. in 2004 (S. Chouin and F. Schaffner, unpublished data). Since this batch was immediately sprayed with insecticide, there is no further evidence that it became established. Moreover, there is no evidence that it is technically an invasive species, as it has not been shown to invade further. It breeds in tree-holes, tires, and other artificial containers, and although primarily zoophilic in its native range, it has been known to opportunistically bite humans (Freier and Grimstad 1983). Its current northern distribution in the U.S. and its ability to overwinter as diapausing eggs and utilize artificial container habitats as aquatic habitats, renders this species a risk for establishment in Europe, particularly given that climate would not appear to be a limiting factor based on its existing range.

A. triseriatus is a known vector of LACV, which can cause serious disease in humans, and is the most common cause of pediatric arboviral encephalitis in the U.S., with 42-172 cases reported annually (1960s-1990s). Case numbers, however, are suspected to be underestimated (McJunkin et al. 2001; Borucki et al. 2002). Jamestown canyon virus has repeatedly been isolated from field-collected A. triseriatus in the U.S. (Andreadis et al. 2008), and the mosquito has also been suggested to be a possible bridge vector for WNV following isolation of the virus from field collections (Centers for Disease Control and Prevention 2009), and demonstration of vector compe- tence under laboratory conditions (Styler et al. 2007). Other vector competence studies have shown its ability to transmit VEEV (Davis et al. 1966), EEEV, Western equine encephalitis virus (WEEV), DENV, SLEV, and YFV under laboratory conditions (Freier and Grimstad 1983).

\section{Aedes koreicus}

Aedes (Finlaya) koreicus, originating from Korea, was recently found in Belgium (Versteirt et al., unpublished data), and in Italy (Capelli et al. 2011), the first locations outside its native region. To date, the species is only established in a small region of eastern Belgium, where it appears not to be spreading, and in a region of northern Italy. As with the other invasive species, it is well adapted to survive human-induced transport over long distances (e.g., tires), can tolerate cold winter temperatures, and exploits artificial containers, and also semi-natural larval habitats (e.g., puddles). In its native range, this species is a human-biter, with a greater preference for human habitations than $A$. japonicus. It is linked to the transmission of JEV (Miles 1964), with suggestions that it may also transmit Dirofilaria (Feng 1938).

\section{Culex vishnui}

Another mosquito species, Culex (Culex) vishnui, has been reported from Albania, supposedly having been accidentally introduced (Adhami 1987). However, the species can be confused with Culex tritaeniorhynchus, which also occurs in parts of the Balkans. Thus its presence in Albania remains to be confirmed, and whether the species is invasive is unclear. This Oriental species is considered a major vector of JEV in Asia (Sucharit et al. 1989), and has been found infected in nature by WNV (Hubalek and Halouzka 1999).

\section{Risk pathways into Europe}

The global transportation of used tires presents the greatest risk of importation of invasive mosquitoes to Europe (Table 1), and this pathway has been largely responsible for the importation and spread of A. albopictus. For all invasive aedine mosquito species, the ability to exploit these container habitats by laying drought-resistant eggs that can withstand the long journeys between continents has facilitated their global dispersal. Dispersal of infested tires from the site of importation throughout inland regions has further facilitated the rapid spread and establishment of these mosquitoes.

Lucky bamboo, a water-based plant imported from Asia, was implicated in the importation of A. albopictus into California (Madon et al. 2002), and more recently in the Netherlands (since 2005) (Scholte et al. 2007). Despite attempts to transport plants in gel as opposed to water, this mosquito continues to be reported at sites using this method of importation (Scholte et al. 2008). So far, these populations in Europe have not spread beyond greenhouses, suggesting that these populations are tropical strains (i.e., unable to survive winter temperatures).

The movement of $A$. albopictus through public or private ground transport has been suggested as the main route of dispersal along highway systems from Italy into southern Switzerland (Ticino) and southern Germany, and from Italy into southern France (French Riviera) and north-eastern Spain (e.g., Barcelona), and possibly also to the Balkan countries, Greece, and Malta (e.g., via ferry traffic) (European Centre for 
Disease Prevention and Control 2009; Table 2). In eastern Europe there are concerns that $A$. aegypti could be introduced from Russia, Abkhazia, and Georgia to other countries bordering the Black Sea via road or sea traffic.

The potential exists for further spread of invasive mosquitoes through air and sea travel within Europe, and this presents a pathway by which $A$. aegypti could be imported into mainland Europe from Madeira (Almeida et al. 2007), or indeed from other overseas associated territories.

\section{Biotic and abiotic factors constraining establishment in Europe}

There is limited information on the environmental constraints governing the distribution of several of these exotic species (e.g., A. atropalpus, A. japonicus, A. koreicus, and A. triseriatus). However, three of these species occur widely in the U.S., including more temperate regions, suggesting that winter temperatures might not be a limiting factor. Aedes atropalpus is known to have established in the Netherlands, Aedes japonicus in Switzerland, Germany, Austria, Slovenia, and Belgium, and Aedes koreicus in Belgium and northern Italy.

Aedes albopictus, unlike $A$. aegypti, has adapted to temperate climates (Hawley, 1988), and there are reports of them becoming partially endophilic, having been found biting indoors (Valerio et al. 2009), and utilizing indoor containers for laying eggs (Dieng et al. 2010). The production of eggs that enter diapause (stimulated by changes in photoperiod), which withstand cold winter temperatures (Hawley 1988; Medlock et al. 2006), as well as cold acclimation of adult females (Romi et al. 2006), have facilitated its spread in northern states in the U.S. (Hawley, 1988), and will permit its survival in parts of northern Europe. Specific mapping and modeling of the most likely areas for establishment of A. albopictus in Europe, and the potential spread with climate change is available from the ECDC (2009). There are a number of articles on $A$. albopictus that detail the likely winter isothermic thresholds $\left(0^{\circ} \mathrm{C}\right.$ to $\left.-5^{\circ} \mathrm{C}\right)$ for egg survival, specific temperatures for adult survival $\left(>9^{\circ} \mathrm{C}\right.$; Roiz et al. 2010), and the critical photoperiod (12-14 h of daylight) that initiates the onset of diapausing eggs (Mitchell 1995; Medlock et al. 2006; Benedict et al. 2007; Severini et al. 2008; Straetemans 2008, European Centre for Disease Prevention and Control 2009), but what is clear is that European populations of $A$. albopictus are evolving and adapting to their local environments (Severini et al. 2008; European Centre for Disease Prevention and Control, 2009).

Although no risk maps are currently available for $A$. aegypti, it is likely that their intolerance to low winter temperatures will limit their survival to southern Europe. Furthermore, evidence of A. albopictus outcompeting A. aegypti in North America (Jansen and Beebe 2010) could further affect the ability for this mosquito to establish widely in Europe, as they use similar larval habitats. Competitive constraints related to other invasive mosquito species include the displacement of A. triseriatus by A. japonicus in the U.S. (Andreadis and Wolfe 2010), and possibly of Culex pipiens by A. japonicus in Switzerland (Schaffner et al. 2009). During studies in Belgium, it was observed that the presence of A. japonicus leads to a shift in the phenology of C. pipiens, and to an increase in C. pipiens mortality (Coosemans et al. 2009). The larvae of $A$. japonicus are highly competitive and this appears to impact negatively on C. pipiens. It is postulated that, at least for Belgium, a strong competitive exclusion may lead to a change in the dominant species in the country.

Regarding fecundity and dispersal, all invasive aedine species have a multi-voltine life history (e.g., many generations per breeding season), catholic feeding habits (though A. aegypti has a strong human-feeding preference), and at least two of them have limited flight dispersal ranges $(<200 \mathrm{~m}$ for A. albopictus; Turell et al. 2005; <100 m for A. aegypti; Reiter 2010). The continental dispersal of these species is therefore reliant largely on the pathways discussed above (e.g., trade and transportation). Their abundance is directly related to summer temperatures, the availability of aquatic habitats (e.g., not necessarily related to rainfall where water is stored), and the availability of blood hosts. Owing to their non-specific feeding habits, they are able to exploit all available blood hosts, which in turn enhances the potential transmission of zoonotic pathogens.

Additional environmental preferences and constraints related to their favored oviposition sites, their indoor/outdoor resting behavior, the amount of organic material permissible in their aquatic habitats, their preference for sunlit/shaded habitats for feeding and resting, and the degree of domesticity, all vary between species. For example, A. albopictus was typically an aggressive exophilic blood feeder; however in Italy, at least, it readily feeds and rests indoors (Valerio et al. 2009), and there is also evidence of it using indoor aquatic habitats (Dieng et al. 2010). These are of particular importance in relation to predicting their spread and planning their control.

It is generally assumed that most alien species need a lag period to adapt to their new environment, in which it remains at low density, and only when adaptation has occurred do populations start to grow exponentially. The genetic diversity of the invasive species probably also plays an important role in its adaptation and therefore the speed of dispersion. Studies of the genetic structure of A. japonicus in the U.S. (Fonseca et al. 2010) and Belgium (Coosemans et al. 2009) reveal that in both countries multiple introductions probably have occurred. Genetic groups therefore appear to be recombining, increasing species diversity, and thus enhancing the invasive capacity of the species.

\section{Effectiveness of control methods}

The purpose of controlling mosquito populations of importance to public health is to reduce the potential for disease transmission and biting nuisance. This is especially important for diseases such as dengue and chikungunya, for which the control of mosquito populations is the main defense against disease transmission. A number of methods are used in mosquito control (some being more effective than others), and often depend upon the mosquito species that is being targeted. Methods such as source reduction, pesticide application, public education, and biological control are often combined, and these integrated vector management techniques produce the optimal control strategy (Alphey et al. 2010; Abramides et al. 2011).

The implementation of control methods (Table 3) has resulted in the eradication of newly-established populations of mosquitoes in some places. Mosquito control programs are suggested to be more effective against $A$. aegypti (as opposed to A. albopictus) due to its strong urban preference and strong human feeding preference (Gould and Higgs 2009). However, control of $A$. aegypti is complex and needs to involve public 
Table 3. Overview of Currently Available Control Methods for Aedine Container-Breeding Species and Their Challenges

Control method

Sampling - collection

Sampling collection of adults and larvae using larval habitat surveys and intensive use of oviposition and CO2-baited traps. Sticky traps have also been used.

Source reduction

Reducing sites that could provide suitable aquatic habitats for larval development.

Insecticides

Monomolecular films can also be applied to larval habitats which stop larvae and pupae from staying at the surface of the water (Nelder et al., 2010).
Successes and challenges

This methods in combined with insecticides and source reduction was used in New Zealand after the discovery of an Ae. albopictus population at a port. The combination of these methods was successful in the eradication of this population (Holder et al., 2010)

Due to the vast number of breeding sites and containers that these mosquito species can utilise as breeding sites and the difficulty to access private grounds, this can be very difficult to achieve.

The application of insecticides can be logistically challenging due to the wide range of containers these invasive mosquito species can utilise as breeding sites.

Insecticide resistance might jeopardize the application of insecticides e.g. resistance among Ae. albopictus populations in Thailand and more recently in La Reunion have been reported. An insecticide resistance gene ( $\mathrm{Rdl}$ resistance allele) was detected in Ae. albopictus populations collected in La Reunion during 2008 (Tantely et al., 2010).

Indoor residual spraying will have limited impact on these Aedes species as only small proportion of adults show to be endophilic.

Bio-insecticides (Bti and Bs) are the most specific insecticides. All other including monomolecular films have unwanted impact on non-targeted fauna.
Public health

education
Informing people of the risks of invasive mosquito species and their associated disease risks can help reduce the contact people have with infected or nuisance biting mosquitoes.

For both $A$ e. albopictus and Ae. aegypti, the available aquatic habitats in urban areas are largely governed by human activities (e.g. waste containers and storage of water outside), so control methods need to be directed at these factors (Jensen \& Beebe, 2010). Educating people about mosquito habitats and encouraging them to reduce potential aquatic sites around their home, wear protective clothing and use mosquito repellent can also help to reduce mosquito biting and arbovirus transmission. health education and a modification of human behavior (Jansen and Beebe 2010). The use of insecticides, a reduction in potential breeding sites, and increasing public health awareness in Madeira has thus far not been able to eliminate the re-established population (Almeida et al. 2007). For A. albopictus, the use of insecticides in recently-colonized greenhouses in the Netherlands may have contributed to the decline in numbers caught the following year (Scholte et al. 2008). Integrated vector management techniques were intro- duced in an area where A. albopictus are firmly established in Catalonia, Spain, and proved to be successful in reducing the number of eggs in intervention areas compared to control areas (Abramides et al. 2011). However, control of A. albopictus in newly-established areas has been difficult in the U.S., France, and Italy (Paupy et al. 2009), with similar problems in Greece and Spain. In France, although eradication of the initial importations in used tire yards was successful, subsequent introductions via ground transportation have resulted in the 
mosquito becoming a pest problem in southern France and Corsica (Vazeille et al. 2008). There are no specific guidelines on controlling A. japonicus, A. atropalpus, A. koreicus, or $A$. triseriatus, although much of the guidance for other container-breeding species like A. albopictus would probably be equally applicable in a synanthropic setting.

The control techniques discussed above are successful in some cases, but are often not sustainable, which has led to the development of alternative methods that could be used in the future to complement the current conventional methods. Sterile insect technique (SIT) has been under development since the 1970s and was used successfully in controlling agricultural pests (Alphey et al. 2010), but is now ready to be used in large-scale programs for mosquito control (Fu et al. 2010). The use of SIT, however, is still under development with regard to mosquito control, and like the other control techniques already mentioned, it has pros and cons. In a tropical and experimental context, problems associated with SIT are being addressed, and some studies have produced promising results (Boyer et al. 2011). One study produced genetically modified male $A$. aegypt $i$ that contained a gene that limits wing development. Once mated with females, this gene is passed on, resulting in offspring that are unable to fly (Fu et al. 2010). If released into areas were $A$. aegypti mosquitoes are present, this could potentially reduce the number of mosquitoes within the area. Although further studies are needed to assess the effectiveness of this strategy on wild mosquito populations, it is an example of developing new approaches to mosquito control. Furthermore, recent findings demonstrate that Wolbachia-based strategies can also be deployed as a practical approach to control A. aegypti, which will help suppress dengue transmission (Hoffmann et al. 2011; Walker et al. 2011).

\section{Public health significance and risk for Europe}

The establishment of $A$. albopictus and A. aegypti in Europe raises concerns about the autochthonous transmission of arboviral pathogens such as DENV and CHIKV (Almeida et al. 2007), which is further exacerbated by the adaptive capability of viruses to infect new species of mosquitoes. Following the CHIKV epidemics in Indian Ocean areas (2005-2007), which caused millions of cases and significant morbidity and burden on health resources, the virus was imported into the first European country in 2007, and caused an autochthonouslytransmitted CHIKV outbreak in Italy. This outbreak involved local transmission via $A$. albopictus mosquitoes, and resulted in 205 cases (one fatal), with a further 129 suspected cases identified (Rezza et al. 2007). However, the true extent of this outbreak is said to be underestimated (Angelini et al. 2007). In 2010, two autochthonous CHIKV cases were also reported in France following reports of an imported case from Asia (Grandadam et al. 2011). The high viral loads of clinically-ill travelers and the presence of $A$. albopictus likely resulted in the onward transmission of CHIKV in France, and highlights the risk of similar events occurring elsewhere in Europe (Gould et al. 2010).

Worldwide, an estimated 50-100 million dengue cases occur annually (Paupy et al. 2009), and although DENV remains an imported infection in Europe, data from the Institut de Veille Sanitaire (InVS) in France suggest that 420 imported cases were reported in 2007 alone (Ledrans and Dejour Salamanca 2008). In the U.K., 406 imported cases of dengue were reported in 2010, increasing from 166 in 2009 (Health Protection Agency 2011). Severe forms of dengue result in DHF and dengue shock syndrome, with case fatality rates reaching $50 \%$ in untreated cases (Seyler et al. 2009). Increasing reports of travelers returning to Europe with DENV, coupled with the spread of $A$. albopictus, has previously raised concerns over further outbreaks and local transmission of the virus in Europe. This concern was realized in 2010, when A. albopictus was linked to cases of DENV in southern France (La Ruche et al. 2010) and Croatia (Gjenero-Margan et al. 2011), all of which were acquired locally.

Imported yellow fever cases (with a case fatality rate of $75 \%$ ) have been reported from Germany, Belgium, Spain, France, the Netherlands, and Switzerland (Kiehl 1999; Colebunders 2001; Monath and Cetron 2002; Bae et al. 2005). There are concerns that further transmission of this virus could occur if populations of $A$. aegypti become reestablished in Europe.

All aedine species introduced or intercepted in Europe are competent vectors for a number of arboviruses (Table 2). Field isolation and experimental infection studies alone do not indicate that all of these mosquito species could be involved in transmission, but indicate the potential risk induced by the presence of such mosquito species in Europe (Braks et al. 2011). Therefore every 3 months VBORNET generates updated maps of the current distribution status of the exotic mosquito species in Europe, based on a compilation of existing data from various sources provided and shared by the members of the network. This unique map resource is accessible to the public (www.vbornet.eu). For some species, their presence in combination with the importation of arboviruses related to travel and favorable climatic and environmental conditions, has resulted in autochthonous transmission of exotic viruses in Europe. The risk of such events will only increase as travel becomes more frequent and mosquito vectors expand their geographical range, unless effective surveillance and control methods are implemented. This may be further exacerbated by an increasingly favorable climate for the mosquito and the pathogen.

\section{Conclusion}

By their very nature invasive mosquitoes are adaptable, and some species will in time become an established part of the European mosquito fauna, causing nuisance biting where they occur. Their disease vector status is a concern, and further surveillance is essential for all these species on a European scale. In addition, information sharing between medical entomologists, concerned public health professionals responsible for managing disease outbreaks, and policymakers is needed to improve preparedness for vector-borne diseases. If we learn any lesson from the last 20 years, it is that we should not be complacent.

\section{Acknowledgments}

The work was conducted by the European network of medical entomologists and public health experts (VBORNET) under ECDC service contract ECD 2009/018. The authors gratefully acknowledge experts from the network for their input and for sharing updated data on vector distribution in their countries. 


\section{Author Disclosure Statement}

No competing financial interests exist.

\section{References}

Abramides GC, Roiz D, Guitart R, et al. Effectiveness of a multiple intervention strategy for the control of the tiger mosquito (Aedes albopictus) in Spain. Trans R Soc Trop Med Hyg 2011; 105:281-288.

Adhami J. Mushkonjat (Diptera: Culicidae) te Shqiperise, tribu Culicini. Revista Mjekësore 1987; 1-2:82-95 [In Albanian].

Almeida APG, Goncalves YM, Novo MT, et al. Vector monitoring of Aedes aegypti in the Autonomous Region of Madeira, Portugal. Euro Surveill 2007; 12, available online: http:// www.eurosurveillance.org/ViewArticle.aspx?ArticleId=3311

Alphey L, Benedict M, Bellini R, et al. Sterile-insect methods for control of mosquito borne diseases: An analysis. Vector Borne Zoonotic Dis 2010; 10:295-311.

Andreadis JF, Anderson JF, Munstermann LE, et al. Discovery, distribution and abundance of the newly introduced mosquito Ochlerotatus japonicus in Connecticut, USA. J Med Entomol 2001; 38:774-749.

Andreadis TG, Anderson JF, Armstrong PM, et al. Isolations of Jamestown Canyon virus from field collected mosquitoes in Connecticut, USA: a ten year analysis, 1997-2006. Vector Borne Zoonotic Dis 2008; 8:175-188.

Andreadis TG, Wolfe BJ. Evidence for reduction of native mosquitoes with increased expansion of invasive Ochlerotatus japonicus japonicus (Diptera: Culicidae) in the Northeastern United States. J Med Entomol 2010; 47:43-52.

Angelini R, Finarelli AC, Angelini P, et al. Chikungunya in northeastern Italy: a summing up of the outbreak. Euro Surveill 2007; 12, available online: http://www.eurosurveillance.org/View Article.aspx?ArticleId $=3313$

Aranda C, Eritja R, Roiz D. First record and establishment of the mosquito Aedes albopictus in Spain. Med Vet Entomol 2006; 20:150-152.

Bae HG, Drosten C, Emmerich P, et al. Analysis of two imported cases of yellow fever infection from Ivory Coast and The Gambia to Germany and Belgium. J Clin Virol 2005; 33: 274-280.

Beaman JR, Turell MJ. Transmission of Venezuelan equine encephalomyelitis virus by strains of Aedes albopictus (Diptera: Culicidae) collected in North and South America. J Med Entomol 1991; 28:161-164.

Becker N, Huber K, Pluskota B, et al. Ochlerotatus japonicus japonicus - a newly established neozoan in Germany and a revised list of the German mosquito fauna. Eur Mos Bull 2011; 29:88-102.

Benedict MQ, Levine RS, Hawley WA, et al. Spread of the Tiger: Global risk of invasion by the mosquito Aedes albopictus. Vector Borne Zoonotic Dis 2007; 7:76-85.

Boorman JPT, Porterfield JS. A simple technique for infection of mosquitoes with viruses transmission of Zika virus. Trans $\mathrm{R}$ Soc Trop Med Hyg 1956; 50:238-242.

Borucki MK, Kempf BJ, Blitvich BJ, et al. La Crosse virus: replication in vertebrate and invertebrate hosts. Microbes Infect 2002; 4:341-350.

Boyer S, Gilles J, Merancienne D, et al. Sexual performance of male mosquito Aedes albopictus. Med Vet Entomol 2011; May 24. doi: 10.1111/j.1365-2915.2011.00962.x

Braks M, van der Giessen J, Kretzschmar M, et al. Towards an integrated approach in surveillance of vector-borne diseases in Europe. Parasites Vectors 2011; 4:192.
Buchanan G. Report on the outbreak of yellow fever at Swansea, 1865; 440-468 In: Eighth report of the medical officer of the Privy Council. London, HMSO.

Cancrini G, Frangipane di Regalbono A, Ricci I, et al. Aedes albopictus is a natural vector of Dirofilaria immitis in Italy. Vet Parasitol 2003a; 118:195-202.

Cancrini G, Romi R, Gabrielli S, et al. First finding of Dirofilaria repens in a natural population of Aedes albopictus. Med Vet Entomol 2003b; 17:448-451.

Capelli G, Drago A, Martini S, et al. First report in Italy of the exotic mosquito species Aedes (Finlaya) koreicus, a potential vector of arboviruses and filariae. Parasites Vectors 2011; 4:188. doi:10.1186/1756-3305-4-188

Centers for Disease Control and Prevention. (2009) Mosquito species producing WNV positives by year. Accessed 6/16/ 2010 online: http://www.cdc.gov/ncidod/dvbid/westnile/ mosquitospecies.htm

Chastel C. [The "plague" of Barcelona. Yellow fever epidemic of 1821]. Bull Soc Pathol Exot 1999; 92:405-407.

Colebunders R. Imported case of confirmed Yellow fever detected in Belgium. Euro Surveill 2001; 5, available online: http://www.eurosurveillance.org/ViewArticle.aspx?ArticleId= 2058

Coosemans M, Hendrickx G, Grootaert P, et al. Mosquito vectors of disease: spatial biodiversity, drivers of change, and risk. Final Report. Brussels: Belgian Science Policy 2009; 131 pp. (Research Programme Science for a Sustainable Development)

Coulanges $\mathrm{P}, \mathrm{Clerc} \mathrm{Y}$, Jousset F-X, et al. Dengue à La Réunion: isolement d'une souche à l'Institut Pasteur de Madagascar. Bull Soc Pathol Exot 1979; 72:205-209.

Davis MH, Hogge AL, Corristan EC, et al. Mosquito transmission of Venezuelan equine encephalomyelitis virus from experimentally infected dogs. Am J Trop Med Hyg 1966; 15:227-230.

Dieng H, Saifur RGM, Hassan AA, et al. Indoor-breeding of Aedes albopictus in northern peninsular Malaysia and its potential epidemiological implications. PLoS One 2010; 27:e11790.

European Centre for Disease Prevention and Control (ECDC). Consultation on mosquito-borne disease transmission risk in Europe. ECDC Meeting report 2011, Stockholm, Sweden [cited Feb 2011]. Available from: http://www.ecdc.europa.eu/ en/publications/Publications/1102_MER_Consultation_on_20 mosquito-borne_diseases.pdf

European Centre for Disease Prevention and Control (ECDC). Development of Aedes albopictus risk maps. ECDC Technical report, 2009; Stockholm, Sweden [cited Jun 19, 2009]. Available from: http://www.ecdc.europa.eu/en/publications/ Publications/0905_TER_Development_of_Aedes_Albopictus_ Risk_Maps.pdf

Effer PV, Pang L, Kitsutani P, et al. Dengue fever, Hawaii, 20012002. Emerg Infect Dis 2005; 11:742-749.

Feng LC. The tree hole species of mosquitoes of Peiping, China. Chin Med J 1938; Suppl 2:503-525.

Fonseca DM, Widdel AK, Hutchinson M, et al. Fine-scale spatial and temporal population genetics of Aedes japonicus, a new US mosquito, reveal multiple introductions. Mol Ecol 2010; 19:1559-1572.

Fontenille D, Diallo M, Mondo M, et al. First evidence of natural vertical transmission of yellow fever virus in Aedes aegypti, its epidemic vector. Trans R Soc Trop Med Hyg 1997; 91:533-535.

Freier JE, Beier JC. Oral transmission of La Crosse virus by Aedes atropalpus. Am J Trop Med Hyg 1984; 33:708-714.

Freier JE, Grimstad PR. Transmission of dengue virus by orally infected Aedes triseriatus. Am J Trop Med Hyg 1983; 3:14291434. 
Fu G, Lees RS, Nimmo D, et al. Female-species flightless phenotype for mosquito control. PNAS 2010; 107:4550-4554.

Gatt P, Deeming JC, Schaffner F. First records of Aedes (Stegomyia) albopictus in Malta. Eur Mos Bull 2009; 27:56-64.

Gerhardt RR, Gottfried KL, Apperson CS, et al. First isolation of La Crosse virus from naturally infected Aedes albopictus. Emerg Infect Dis 2001; 7:807-811.

Gjenero-Margan I, Aleraj B, Krajcar D, et al. Autochthonous dengue fever in Croatia, August-September 2010. Euro Surveill 2011; 16:pii $=19805$. Available online: http:// www.eurosurveillance.org/ViewArticle.aspx?ArticleId =19805

Gould EA, Gallian P, De Lamballerie X, et al. First cases of autochthonous dengue fever and chikungunya fever in France: from bad dream to reality? Clin Microbiol Infect 2010; 12:1702-1704.

Gould EA, Higgs S. Impact of climate change and other factors on emerging arbovirus diseases. Trans R Soc Trop Med Hyg 2009; 130:109-121.

Grandadam M, Caro V, Plumet S, et al. Chikungunya virus, southeastern France. Emerg Infect Di. 2011; 17:910-913.

Grimstad PR, Kobayashi JF, Zhang MB, et al. Recently introduced Aedes albopictus in the United States: potential vector of La Crosse virus (Bunyaviridae: California serogroup). J Am Mosq Control Assoc 1989; 5:422-427.

Hawley WA. Biology of Aedes albopictus. J Am Mosq Control Assoc 1988; Suppl 1, 4:2-39.

Hayes EB. Zika virus outside Africa. Emerg Infect Dis 2009; 15:1347-1350.

Health Protection Agency (HPA). Dengue fever cases double among travellers. www.hpa.org.uk. Accessed 17 May 2011.

Hoffmann AA, Montgomery BL, Popovici J, et al. Successful establishment of Wolbachia in Aedes populations to suppress dengue transmission. Nature 2011; 476:454-457.

Holder P, George S, Disbury M, et al. A biosecurity response to Aedes albopictus (Diptera: Culicidae) in Auckland, New Zealand. J med Ent 2010; 47:600-609. DOI: 10.1603/ME09111 [online].

Holick J, Kyle A, Ferraro W, et al. Discovery of Aedes albopictus infected with West Nile virus in southeastern Pennsylvania. J Am Mosq Control Assoc 2002; 18:131.

Hubalek Z, Halouzka J. West Nile Fever-a reemerging mosquitoborne viral disease in Europe. Emerg Infect Dis 1999; 5:643-650.

Huber K, Jost A, Becker N, et al. Surveillance and control of the invasive and established species Ochlerotatus japonicus in south Germany. Presentation to the 6th European Mosquito Control Association Workshop, 12-15th September 2011, Budapest, Hungary.

Invasive Species Specialist Group. (2009). Global Invasive Species Database-Aedes albopictus. Accessed 08/26/2010 available online: http://www.issg.org/database/species/ecology .asp? $\mathrm{si}=109 \& \mathrm{fr}=1 \& \mathrm{sts}=$ sss\&lang $=\mathrm{EN}$

Jansen CC, Beebe NW. The dengue vector Aedes aegypti: What comes next. Microbes Infect 2010; 12:272-279.

Kawada H, Maekawa Y, Abe M, et al. Spatial distribution and pyrethroid susceptibility of mosquito larvae collected from catch basins in parks in Nagasaki city, Nagasaki, Japan. Jpn J Infect Dis 2010; 63:19-24.

Kiehl W. Suspected case of haemorrhagic fever confirmed as yellow fever in Germany. Euro Surveill 1999; 3. Available online: http://www.eurosurveillance.org/ViewArticle.aspx? ArticleId $=1350$

La Ruche G, Souarès $Y$, Armengaud A, et al. First two autochthonous dengue virus infections in metropolitan France, September 2010. Euro Surveill 2010; 15:pii=19676. Available online: http://www.eurosurveillance.org/ViewArticle.aspx? ArticleId $=19676$

Ledrans M, Dejour Salamanca D. Cas importés de chikungunya et de dengue en France métropolitaine. Institut de veille sanitaire, Saint-Maurice, 2008; 28. Accessed 08/26/2010 available online: http://www.invs.sante.fr/publications/2008/cas_ importes_chik_dengue/index.html

Marchette NJ, Garcia R, Rudnick A. Isolation of Zika virus from Aedes aegypti mosquitoes in Malaysia. Am J Trop Med Hyg 1969; 18:411-415.

Madon MB, Mulla MS, Shaw MW, et al. Introduction of Aedes albopictus (Skuse) in southern California and potential for its establishment. J Vector Ecol 2002; 27:149-154.

McJunkin JE, De Los Reyes EC, Irazuzta JE, et al. La Crosse encephalitis in children. N Engl J Med 2001; 3:801-807.

Medlock JM, Avenell D, Barrass I, et al. Analysis of the potential for survival and seasonal activity of Aedes albopictus in the United Kingdom. J Vector Ecol 2006; 31:292-304.

Miles JAR. Some ecological aspects of the problems of arthropodborne animal viruses in the Western Pacific and South East Asia regions. Bull World Health Organ 1964; 30:197-210.

Mitchell CJ. Geographic spread of Aedes albopictus and potential for involvement in arbovirus cycles in the Mediterranean basin. J Vector Ecol 1995; 20:44-58.

Mitchell CJ, Niebylski ML, Smith GC, et al. Isolation of eastern equine encephalitis virus from Aedes albopictus in Florida. Science 1992; 257:526-527.

Monath TP, Cetron MS. Prevention of yellow fever in persons travelling to the tropics. Clin Infect Dis 2002; 34:13691378.

Nelder M, Kesavaraju B, Farajollahi A, et al. Suppressing Aedes albopictus, an emerging vector of dengue and chikungunya viruses, by a novel combination of a monomolecular film and an insect-growth regulator. Am J Trop med Hyg 2010; 82:831837. DOI: 10.4269/ajtmh.2010.09-0546 [online].

Pampiglione S, Rivasi F, Angeli G, et al. Dirofilariasis due to Dirofilaria repens in Italy, an emergent zoonosis: Report of 60 new cases. Histopathology 2001; 38:344-354.

Paupy C, Delatte H, Bagny L, et al. Aedes albopictus, an arbovirus vector: From the darkness to the light. Microbes Infect 2009; 11:1177-1185.

Petric D. Monitoring of invasive vector mosquitoes and vectorborne diseases (in Serbian). Report to Administration for Environmental Protection, Novi Sad City 2009: 1-9.

Pialoux G, Gauzere BA, Jaurequiberry S, et al. Chikungunya, an epidemic arbovirus. Lancet Infect Dis 2007; 5:319-327.

Pierre V, Thiria J, Rachou E, et al. Epidémie de dengue 1 à la Réunion en 2004. Journées de veille sanitaire 2005; Paris, Abstract book 64. Available online: http://www.invs.sante.fr/ publications/2005/jvs_2005/poster_13.pdf

Ramchurn SK, Moheeput K, Goorah SS. An analysis of a shortlived outbreak of dengue fever in Mauritius. Euro Surveill 2009; 14. Available online: http://www.eurosurveillance.org/ ViewArticle.aspx?ArticalId=19314

Reinert JF, Harbach RE, Kitching IJ. Phylogeny and classification of Aedini (Diptera: Culicidae), based on morphological characters of all life stages. Zool J Linn Soc 2004; 142:289-368.

Reinert JF, Harbach RE, Kitching IJ. Phylogeny and classification of Finlaya and allied taxa (Diptera: Culicidae: Aedini) based on morphological data from all life stages. Zool J Linn Soc 2006; 148:1-101.

Reinert JF, Harbach RE, Kitching IJ. Phylogeny and classification of Ochlerotatus and allied taxa (Diptera: Culicidae: Aedini) 
based on morphological data from all life stages. Zool J Linn Soc 2008; 153:29-114.

Reinert JF. New classification for the composite genus Aedes (Diptera: Culicidae: Aedini), elevation of subgenus Ochlerotatus to generic rank, reclassification of the other subgenera, and notes on certain subgenera and species. J Am Mosq Cont Assoc 2000; 16:175-188.

Reiter P. Yellow fever and dengue: A threat to Europe? Euro Surveill 2010; 15. Available online: http://www.euro surveillance.org/ViewArticle.aspx?ArticleId=19509

Rezza G, Nicoletti L, Angelini R, et al. Infection with CHIKV in Italy: an outbreak in a temperate region. Lancet 2007; 370: 1840-1846.

Roiz D, Rosa R, Arnoldi D, et al. Effects of temperature and rainfall on the activity and dynamics of host-seeking Aedes albopictus females in Northern Italy. Vector Borne Zoonotic Dis 2010; 10:811-816.

Romi R, Sabtinelli G, Savelli LG, et al. Identification of a North American mosquito species Aedes atropalpus in Italy. J Am Mos Control Assoc 1997; 13:245-246.

Romi R, Severini F, Toma L. Cold acclimation and overwintering of female Aedes albopictus in Roma. J Am Mos Control Assoc 2006; 22:149-151.

Rosen L. Dengue in Greece in 1972 and 1982 and the pathogenesis of DHF: New data and a different conclusion. Am J Trop Med Hyg 1986; 35:642-653.

Sardelis MR, Dohm DJ, Pagac B, et al. Experimental transmission of eastern equine encephalitis virus by Ochlerotatus japonicus japonicus. J Med Entomol 2002b; 39:480-484.

Sardelis MR, Turell MJ, Andre RG. Experimental transmission of St Louis encephalitis virus by Ochlerotatus japonicus japonicus. J Am Mos Control Assoc 2003; 19:159-162.

Sardelis MR, Turell MJ, Andre RG. Laboratory transmission of La Crosse virus by Ochlerotatus j. japonicus. J Med Entomol 2002a; 39:635-639.

Sardelis MR, Turell MJ. Ochlerotatus japonicus japonicus in Frederick County, Maryland: discovery, distribution and vector competence for West Nile virus. J Am Mos Control Assoc 2001; 17:137-141.

Sardelis MR, Turell MJ, O'Guinn ML, et al. Vector competence of three North American strains of Aedes albopictus for West Nile virus. J Am Mos Control Assoc 2002c; 18:284-289.

Schaffner F, Chouin S, Guilloteau J. First report of Ochlerotatus japonicus japonicus in metropolitan France. J Am Mos Control Assoc 2003; 19:1-5.

Schaffner F, Kaufmann C, Hegglin D, et al. The invasive mosquito Aedes japonicus in Central Europe. Med Vet Entomol 2009; 23:448-451.

Schneider K. Breeding of Ochlerotatus japonicus japonicus $80 \mathrm{~km}$ north of its known range in southern Germany. Euro Mos Bull 2011; 29:129-132.

Scholte EJ, Den Hartog W, Dik M, et al. Introduction and control of three invasive mosquito species in the Netherlands, JulyOctober 2010. Euro Surveill 2010; 15:11.

Scholte EJ, Dijkstra E, Blok H, et al. Accidental importation of the mosquito Aedes albopictus into the Netherlands: a survey of mosquito distribution and the presence of dengue virus. Med Vet Entomol 2008; 22:352-358.

Scholte EJ, Dijkstra E, Ruijs H, et al. The Asian tiger mosquito in the Netherlands: should we worry? Proceedings of the Section Experimental and Applied Entomology. Netherlands Entomological Society 2007; 18:131-136.

Scholte EJ, Hartog WD, Braks M, et al. First report of a North American invasive mosquito species Ochlerotatus atropalpus in the Netherlands, 2009. Euro Surveill 2009; 14. Accessed 08/ 26/2010, available online: http://www.eurosurveillance.org/ ViewArticle.aspx?ArticleId $=19400$

Severini F, Di Luca M, Toma L, et al. Aedes albopictus in Rome: results and perspectives after 10 years of monitoring. Parassitologica 2008; 50:121-123.

Seyler T, Grandesso F, Strat YL, et al. Assessing the risk of importing dengue and chikungunya viruses to the European Union. Epidemics 2009; 1:175-184.

Soumahoro MK, Fontenille D, Turbelin C, et al. Imported chikungunya virus infection. Emerg Infect Dis 2010; 16:162163.

Straetemans M. Vector-related risk mapping of the introduction and establishment of Aedes albopictus in Europe. Euro Surveill 2008; 13. Accessed 08/26/2010, available online: http:// www.eurosurveillance.org/ViewArticle.aspx?ArticleId $=8040$

Styer LM, Kent KA, Albright RG, et al. Mosquitoes inoculate high doses of West Nile Virus as they probe and feed on live hosts. PLoS Pathogens 2007; 3:e132.

Sucharit S, Surathin K, Shrestha SR. Vectors of Japanese encephalitis virus (JEV): species complexes of the vectors. Southeast Asian J Trop Med Public Health 1989; 20:611621.

Takashima I, Rosen L. Horizontal and vertical transmission of Japanese encephalitis virus by Aedes japonicus. J Med Entomol 1989; 26:454-458.

Tanaka K, Mizusawa K, Saugstad ES. A revision of the adult and larval mosquitoes of Japan (including the Ryukyu Archipelago and the Ogasawara islands) and Korea (Diptera: Culicidae). Contributions of the American Entomological Institute 1979; 16:1-987.

Tantely ML, Tortosa $\mathrm{P}$, Alout $\mathrm{H}$, et al. Insecticide resistance in Culex pipiens quinquefasciatus and Aedes albopictus mosquitoes from La Reunion Island. Insect Biochem Mol Biol 2010; 40: 317-324.

Turell MJ, Beaman JR. Experimental transmission of Venezuelan equine encephalomyelitis virus by a strain of Aedes albopictus (Diptera: Culicidae) from New Orleans, Louisiana. J Med Entomol 1992; 29:802-805.

Turell MJ, Beaman JR, Neely GW. Experimental transmission of eastern equine encephalitis virus by strains of Aedes albopictus and A. taeniorhynchus (Diptera: Culicidae). J Med Entomol 1994; 31:287-290.

Turell MJ, Dohm DJ, Sardelis MR, et al. An update on the potential of North American mosquitoes to transmit West Nile virus. J Med Entomol 2005; 42:57-62.

Turell MJ, O'Guinn ML, Dohm DJ, et al. Vector competence of North American mosquitoes for West Nile virus. J Med Entomol 2001; 38:130-134.

Valerio L, Marini F, Bongiorno G, et al. Host-feeding patterns of Aedes albopictus in urban and rural contexts within Rome Province, Italy. Vector Borne Zoonotic Dis 2009; 10: 291-294.

Vazeille M, Jeannin C, Martin E, et al. Chikungunya: A risk for Mediterranean countries? Acta Tropica 2008; 105: 200-202.

Versteirt V, Schaffner F, Garros C, et al. Introduction and establishment of the exotic mosquito species Aedes japonicus japonicus in Belgium. J Med Entomol 2009; 46:1464-1467.

Walker T, Johnson PH, Moreira LA, et al. The wMel Wolbachia strain blocks dengue and invades caged Aedes aegypti populations. Nature 2011; 476:450-453.

Wichmann O, Jelinek T. Surveillance of imported dengue infections in Europe. Euro Surveill 2003; 7. Available online: 
http://www.eurosurveillance.org/ViewArticle.aspx?ArticleId= 2271

Wilder-Smith A, Ooi EE, Vasudevan SG, et al. Update on dengue: epidemiology, virus evolution, antiviral drugs, and vaccine development. Curr Infect Dis Rep 2010; 12: 157-164.

Yunicheva YU, Ryabova TE, Markovich NY, et al. First data on the presence of breeding populations of the Aedes aegypti L. mosquito in Greater Sochi and various cities of Abkhazia. Meditsinskaia Parazitologiia I Parazitarnye Bolezni 2008; 3: $40-43$.
Address correspondence to: Jolyon Medlock

Medical Entomology E Zoonoses Ecology Group Microbial Risk Assessment Emergency Response Division Health Protection Agency Porton Down Salisbury, SP4 0JG United Kingdom

E-mail: jolyon.medlock@hpa.org.uk 